\title{
Imaging approaches in functional assessment of implantable myogenic biomaterials and engineered muscle tissue
}

\author{
Kyle J. Edmunds (1), Paolo Gargiulo $(1,2)$ \\ (1) Institute for Biomedical and Neural Engineering, University of Reykjavík; (2) University \\ Hospital Landspítali, Reykjavík, Iceland
}

\begin{abstract}
The fields of tissue engineering and regenerative medicine utilize implantable biomaterials and engineered tissues to regenerate damaged cells or replace lost tissues. There are distinct challenges in all facets of this research, but functional assessments and monitoring of such complex environments as muscle tissues present the current strategic priority. Many extant methods for addressing these questions result in the destruction or alteration of tissues or cell populations under investigation. Modern advances in non-invasive imaging modalities present opportunities to rethink some of the anachronistic methods, however, their standard employment may not be optimal when considering advancements in myology. New image analysis protocols and/or combinations of established modalities need to be addressed. This review focuses on efficacies and limitations of available imaging modalities to the functional assessment of implantable myogenic biomaterials and engineered muscle tissues.

Key Words: Imaging, Tissue Engineering, Regenerative Medicine, Implantable myogenic biomaterials, Engineered muscles
\end{abstract}

Eur J Transl Myol - Basic Appl Myol 2015; 25 (2): 63-76

Tissue engineering and regenerative medicine are rapidly growing fields of research that aim to use a multi-disciplinary approach to restore or replace tissues that have either been damaged or lost through diseases or trauma. Although strategies for restoring function and structure typically vary considerably, most investigations involve the use of cells, biomaterial scaffolds, and various inducible factors, that are either first incubated in bioreactors or directly implanted in vivo. The complex environments that these components and methodologies generate present unique challenges - not only in generating functional engineered tissue, but in monitoring and assessing outcomes both in vitro and in vivo.

Of the many tissue types under investigation in these fields, the creation of new muscle through tissue engineering represents a promising alternative to the replacement of tissue after either severe damage or degeneration from various myopathies. ${ }^{1-4}$ Surgical reconstruction in patients with significant muscle tissue loss typically utilizes transferred tissue from local and/or distant sites, which often results in significant local denervation, functional loss, and/or volume deficiency. 5 The engineering of lost connective, nervous, and muscular tissue on a patient-specific basis has been suggested by many to represent the future of muscle surgical reconstruction. ${ }^{7-9}$ Likewise, tissue engineering approaches have been suggested for treating musculoskeletal myopathies such as spinal muscular atrophy or Duchenne muscular dystrophy (DMD). ${ }^{10-12}$ However, a common challenge remains in either approach to muscular regeneration - how best to non-invasively assess the viability and function of engineered or extant muscle tissue, both in vitro and in vivo.

\section{Functional Assessment in Myology}

As in every focus of tissue engineering, engineered muscle tissues should exhibit biomimetic functional properties and recapitulate native structure specifically with regards to densely packed and uniformly aligned myofibers throughout the tissue volume. ${ }^{1}$ As such, methods for assessing cellular viability, proliferation, biological integration, and/or differentiation are crucial to identify optimal strategies. What is herein broadly referred to as the "functional assessment" of engineered muscle tissue and/or implantable biomaterials depends largely on the methodology employed in the particular investigation. In the case where large volumes of muscle, nervous, and connective tissue must be replaced, regeneration may not be possible by the exclusive transplantation of 

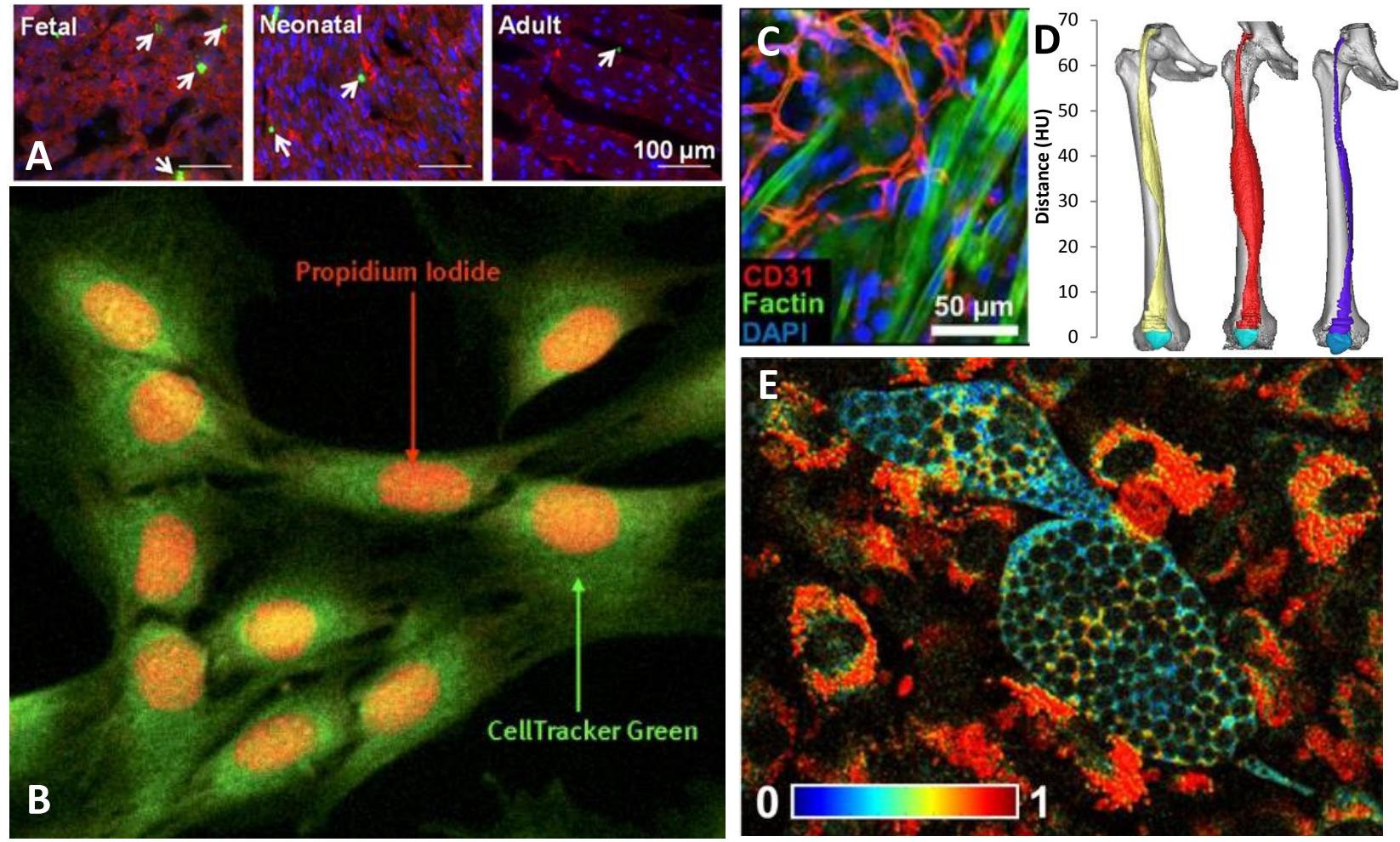

Fig 1. Types of functional assessment metrics for various tissue engineering studies. A) Proliferation of cardiomyocytes measured by immunohistochemical staining of phosphohistone $\mathrm{H}^{15}$. B) Muscle cells viability measured in cells stained with CellTracker ${ }^{\mathrm{TM}}$ Green and propidium iodide showing dying myocytes. ${ }^{136} \boldsymbol{C}$ ) Periphery of implanted engineered muscle showing neonatal rat satellite cells and their myogenic predifferentiation via $f$-actin filamentous formation and integration with extant, CD31-labeled endotheilial cells. ${ }^{137}$ D) $C T$ reconstructions of denervated thigh muscle that was electrically stimulated for growth, highlighting a possible modality for measuring myogenesis in engineered muscle tissue. $\left.{ }^{143,144} \boldsymbol{E}\right)$ Changes in redox ratios observed in adipogenic differentiation with TPEF along with characteristic, non-autofluorescent lipid droplets. $^{40}$

autologous cells - rather, a bioreactor-based approach may be prescribed, wherein large-volume tissue formation is initiated and controlled prior to implantation. In contrast, in considering general musculoskeltal degeneration due to a particular myopathy, regeneration might be optimally achieved through the injection of myoblasts or relevant multipotent progenitor cells, both with or without biomaterials and/or therapeutic factors, to stimulate the release of soluble signals, the formation of extracellular matrix (ECM), and/or the incorporation of new tissues. In either approach to regeneration, functional assessment of engineered cells or largevolume tissues remains a crucial step in quantitatively andnon-destructively characterizing and monitoring the dynamic and complex interactions of the host site and engineered cells and/or large-volume of muscle tissue. ${ }^{13}$ Such assessments are crucial in understanding the optimal methods for rational control of muscle tissue structure and function via complex, temporallydependent interactions between cells, biomolecules, and engineered scaffolds.

\section{Traditional Functional Assessments and the Expanding Role of Imaging}

There are many standard analysis methods currently available for tissue engineers to be utilized at both the individual cell and whole-tissue levels, but all of them have their innate limitations (Fig. 1). For example, metabolomic assays offer only a temporal snapshot of tissue physiological function - an assessment that likewise kills the construct in question. ${ }^{4,14,15}$ MTT assays can be used as a quick and relatively simple assay for cellular metabolic activity (and, indirectly, viability) but is limited by the use of the tetrazolium dye, as only certain cells can participate in its reduction. ${ }^{16}$ Other methods such as fluorescent immunohistological staining or tissue biopsy are labor intensive, invasive, and destructive; thus, multiple timepoints and endpoint studies must be performed and temporal correlation inferred. Rendering engineered cells unrecoverable is of particular concern in cell therapy investigations, where cells and implantable 


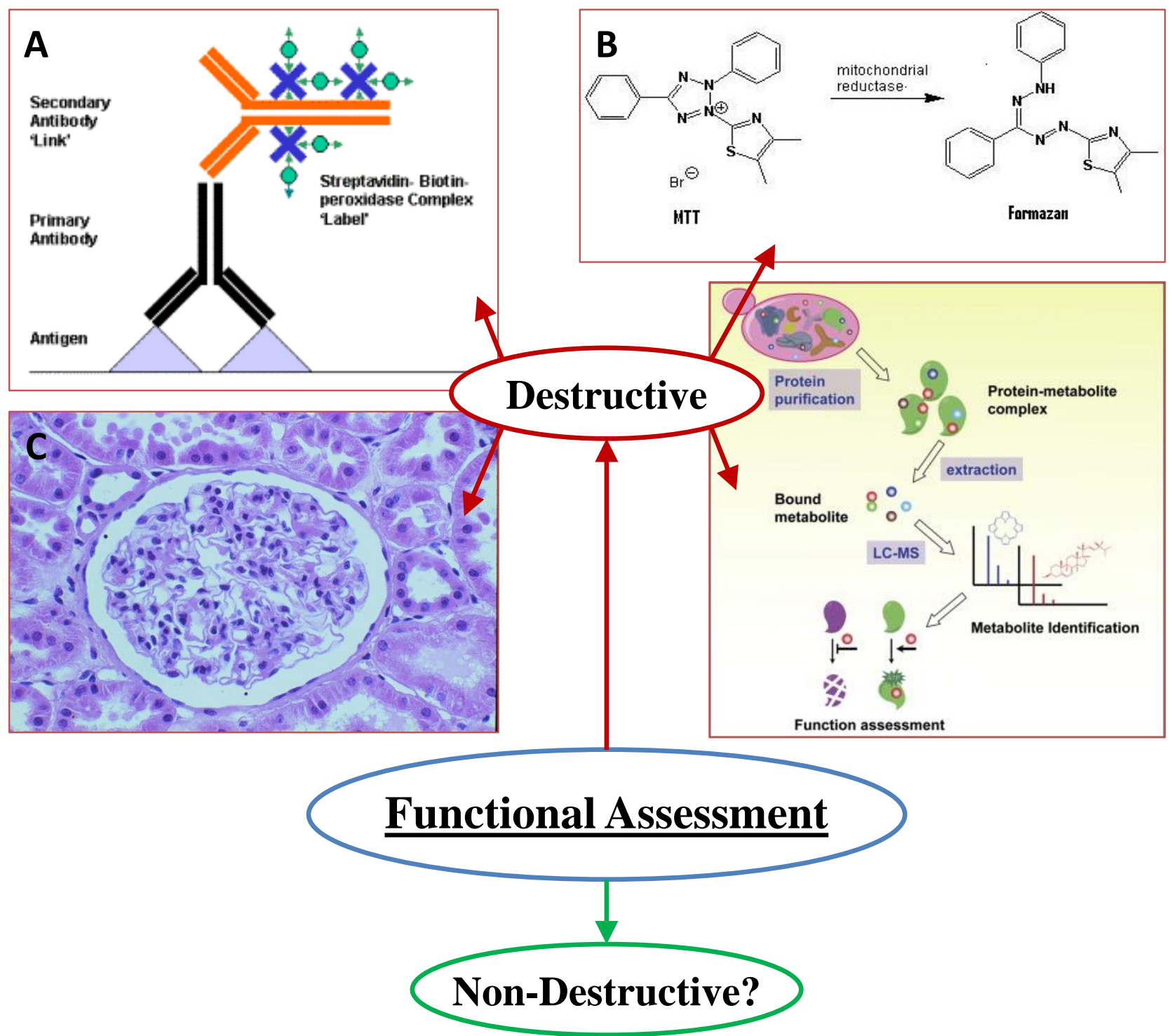

Fig. 2 Standard destructive methods for the functional analysis of engineered tissue

biomaterials are introduced to their hosts and tracked over time to assess both viability and cell fate. ${ }^{13,17-20}$ To alleviate these concerns, several noninvasive imaging techniques have recently been developed to obtain information on both cell metabolism and fate in engineered tissues. ${ }^{21-29}$ These methods exploit a number of intrinsic cellular phenomena, such as autofluorescence and tissue glycolysis. While many of these methods have shown considerable promise, it is important to comprehensively distill their respective benefits and limitations, as there exists a clear need for the development of an assessment platform that operates in real-time, at relevant tissue depths and in vivo.

High resolution imaging methods that can allow for noninvasive, real-time assessment of cellular and tissue-level function within engineered muscle could provide significant aid to the fields of tissue engineering and regenerative medicine. These methods have readily been identified as a strategic priority in other venues of tissue engineering research, and extant applicable imaging modalities have been identified; however, their employment via standard methods may not be optimal when considering advances in myology research. ${ }^{30}$ While researchers continue to address many of these concerns, there is yet relatively little literature offering a comprehensive assessment of modern approaches to noninvasive functional imaging of engineered muscle and myogenic biomaterials. This review presents these modalities to guide and promote current discussion on the development and evaluation of optimal methods, in particular for myology applications. 


\section{Two-Photon Excited Fluorescence}

As previously mentioned, non-invasive imaging techniques that take advantage of the endogenous fluorophores of cells have been in development for decades. $^{31-34}$

http://www.ncbi.nlm.nih.gov/pmc/articles/PMC384221 2/ - R8. Many of these modalities have investigated the quantification of cellular and tissue metabolic state through fluorescent excitation of both the primary electron donor and receptor in cellular respiration: nicotinamide adenine dinucleotide (NADH) and flavin adenine dinucleotide (FAD), respectively. In its reduced form, NADH may be fluorescently excited at $350 \mathrm{~nm}$ (emission maximum at $460 \mathrm{~nm}$ ), whereas its oxidized counterpart, NAD+, is non-fluorescent. ${ }^{35}$ Likewise, FAD has fluorescent excitation and emission maxima of $450 \mathrm{~nm}$ and $535 \mathrm{~nm}$, respectively. ${ }^{36}$ During high tissue metabolic demand, the ratio of mitochondrial NADH to NAD+ decreases, resulting in a markedly reduced fluorescent profile which therein allows for the single-channel $(350 \mathrm{~nm})$ assessment of respiration within the mitochondrial matrix space. ${ }^{37,38}$ Alternatively, both an $350 \mathrm{~nm}$ and $450 \mathrm{~nm}$ excitation may be employed to obtain an approximation of the mitochondrial oxidation-reduction ratio, or the ratio of the fluorescent intensity of FAD to that of NADH.

Two-photon excited fluorescence (TPEF) is a promising method for the imaging of mitochondrial redox ratios in vivo, since it offers high resolution (approx. $400 \mathrm{~nm}$ ) at relatively large tissue depths (approx. $1 \mathrm{~mm})^{36,39,40}$ Two-photon excitation occurs when a fluorophore interacts with two photons whose energies are equal to half of the excitation energy of that particular fluorophore. These fluorophores can be the same target probed by single-photon fluorescence. $^{41}$ Both NADH and FAD can be readily excited by two-photon excitation at near infrared wavelengths $(650-900 \mathrm{~nm})$. Excitation wavelengths from 710-780 nm results in NADH excitation, whereas oxidized flavoprotein in FAD may be excited from $700-900 \mathrm{~nm}$, and these wavelength ranges are both relatively safe, yet highly penetrative, due to reduced scattering and absorption as the excitation volume is inherently confined by its non-linear dependence on incident beam intensity. ${ }^{42-44}$ As such, many recent investigations have employed TPEF of NADH and FAD to monitor metabolism of many tissue types, including cardiac, corneal, pancreatic, and brain. ${ }^{42,} 44-52$ TPEF is a promising modality for the functional assessment of glycolysis and oxidative phosphorylation in engineered tissues due primarily to its nondestructive use of infrared light, as opposed to UV excitation otherwise inherent to single-photon excited fluorescence. However, despite TPEF being a relatively deeply-penetrating optical method, its maximum penetration depth of $1 \mathrm{~mm}$ is its greatest drawback when considering the assessment of deeper tissues.

\section{Photoacoustic Microscopy}

Photoacoustic Microscopy (PAM) is a hybrid modality combining principles of ultrasound detection and what is known as the photoacoustic effect. In PAM, pulses of near-infrared light are absorbed rapidly by a tissue and quickly converted to heat which leads to a transient thermoelastic expansion. This expansion propagates as an ultrasonic wave and is eventually detected by an ultrasound transducer. ${ }^{53,54}$ Structural and functional information of various tissue morphologies can be readily determined, as photoacoustic absorption varies strongly with oxyhemoglobin content. As such, many recent studies have successfully resolved both the structure and oxygenation levels of complex tissues and vasculatures down to the capillary level. ${ }^{55,56}$ PAM has been suggested by many for its utility in tissue engineering applications. Due to its inherent ability to detect functional vasculature, PAM has already been used to resolve angiogenesis in tumors: a crucial metric in assessing the biological integration of engineered tissue. $^{57-59}$ Likewise, neovascularization and cellular distribution within implantable biomaterials, such as porous polymer foams, ${ }^{56,60}$ mesenchymal stem cell seeded hydrogels, ${ }^{61}$ and cell-free hydrogels containing the growth factor FGF- $2,{ }^{62}$ have been monitored using PAM. Introducing contrast agents such as gold

Table 1. Target pathophysiology of various ${ }^{18} \mathrm{~F}$-containing radiopharmaceuticals. ${ }^{92}$
Metabolism
${ }^{18}$ F-fluorodeoxyglucose $\left({ }^{18} \mathrm{~F}\right.$-FDG)
Cell Proliferation
9-(4-fluoro- ${ }^{18}$ F-3-hydroxymethybutyl
Gene Expression 


\section{Imaging of biomaterials and engineered muscle tissue}

Eur J Transl Myol - Basic Appl Myol 2015; 25 (2): 63-76

particles to engineered tissues, biomaterials, or injected cells has likewise proven successful for researchers investigating blood oxygen saturation levels and stem cell trafficking. ${ }^{63-65}$ In general, PAM offers a number of benefits over other functional imaging methods, but its maximum depth of penetration (approx. $3 \mathrm{~mm}$ ) and its dependency on local laser fluence might make longitudinal studies of deeper tissues prohibitively difficult to perform.

\section{Fluorescence-Lifetime Imaging Microscopy}

As previously mentioned, improvements in the field of multiphoton microscopy present a great opportunity for both high-resolution and long-term imaging of engineered tissues and biomaterials. Due to both its intrinsic 3D resolution and high depth of penetration, multiphoton microscopy allows for the investigation of a local environment in femtoliter volumes located deep within tissues. ${ }^{406}$ Investigations utilizing multiphoton microscopy take advantage of the autofluorescent nature of endogenous fluorophores, such as collagen, elastin, porphyrin, flavin, hemoglobin, serotonin, and as previously discussed, NADH and FAD. ${ }^{42,44-52}$ However, using emission wavelengths to discriminate between multiple fluorescent species within the same focal volume is majorly limited by their emission spectra overlap. ${ }^{42}$

Fluorescence-Lifetime Imaging Microscopy (FLIM) is a promising imaging modality that has elicited many successes in monitoring the differentiation of stem cells. ${ }^{21,27,67,68}$ Additionally, FLIM has been shown to have utility in separating NADH and NADPH emission spectra, aiding greatly in the study of the photochemistry of living tissues. ${ }^{23,50,69,70}$ While FLIM has shown considerable flexibility and utility in a number of studies in the field of tissue engineering, there is still much discussion regarding the optimum FLIM analysis methodology.

One such method, known as Phasor analysis, has proven its utility as a fit-free and label-free approach to probing cellular environments and identifying biologically relevant details regarding cell fate. Rather than fitting multiple lifetimes of one or multiple species, Phasor analysis represents each lifetime as a vector defined by its modulation and phase - thereby removing the need for a priori knowledge of each species' specific lifetimes. ${ }^{21}$ This likewise means that relative concentrations of each species can readily be determined by simply ascertaining the ratio of their phasor representations. This method has recently been employed in characterizing the different metabolic and differentiation states of both $C$. Elegans and human endothelial stem cells. ${ }^{21,67}$ (see in particular at ${ }^{14}$

\section{http://www.nature.com/srep/2013/131205/srep} 03432/full/srep03432.html

However, for species that are close to each other on the phasor diagram, phenomena such as photobleaching and quenching could account for significant error in assessing relative species' concentrations. Nonetheless, as a non-invasive, nondestructive, and label-free imaging modality that can identify cellular differentiation and metabolic states, the phasor approach to FLIM is a promising imaging modality for future muscle tissue engineering applications.

\section{Optical Coherence Tomography}

Another potential strategy for the real-time, noninvasive, and label-free assessment of the structure and function of engineered tissue is optical coherence tomography (OCT). OCT is an interferometry technique that uses broadband near-infrared light at wavelengths greater than $800 \mathrm{~nm}$, allowing for deeper tissue penetration (approx. $2000 \mathrm{~mm}$ ) than previouslymentioned near-infrared imaging modalities. ${ }^{70-73}$ OCT has been utilized extensively to monitor cell location, migration, differentiation, and interaction with local biomaterials. ${ }^{74-76}$ Thanks to its near-cellular level resolution, OCT has been employed in investigations that would have otherwise been prohibitively challenging with other imaging modalities, such as the study of structural changes in the retina, ${ }^{77}$ the $3 \mathrm{D}$ characterization of polylactate and chitosan scaffolds, ${ }^{78}$ and the kinetics of cell integration into collagen, agarose, and other hydrogels. ${ }^{72,73,75,79,80}$ In addition, OCT has also been utilized to monitor the optical attenuation of cells that were cultured within agarose gels. ${ }^{81}$ Other studies have utilized OCT to monitor macroscopic tissue regeneration via such processes as calcification in gelatin scaffolds and the growth of skin models. ${ }^{75,79,80,82-85}$

In many recent studies, OCT has been combined with other imaging or processing techniques to image cells and assess their deposition onto engineered tissue scaffolds in vitro. Additionally, the combination of OCT and Doppler velocimetry has revealed a technique that can image micron-level fluid flow, allowing for noninvasive and real-time imaging of engineered tissue rheological and elastic properties. ${ }^{75,83}$ Another type of OCT, known as Time Domain OCT, has likewise been utilized for the noninvasive imaging of the porosity of polymer foam scaffolds that have been seeded with aggregates of cells. ${ }^{86}$ In this investigation, cell proliferation and extracellular matrix deposition could be monitored as a function of the allowable imaging depth and the degree to which porosity could be detected over time. In another type of OCT, whole-field OCT was employed, along with the use of magnetic beads as a contrast agent, to observe changes in cellular morphology within engineered bone tissue in vitro. ${ }^{86}$ Likewise, OCT has been shown 
A

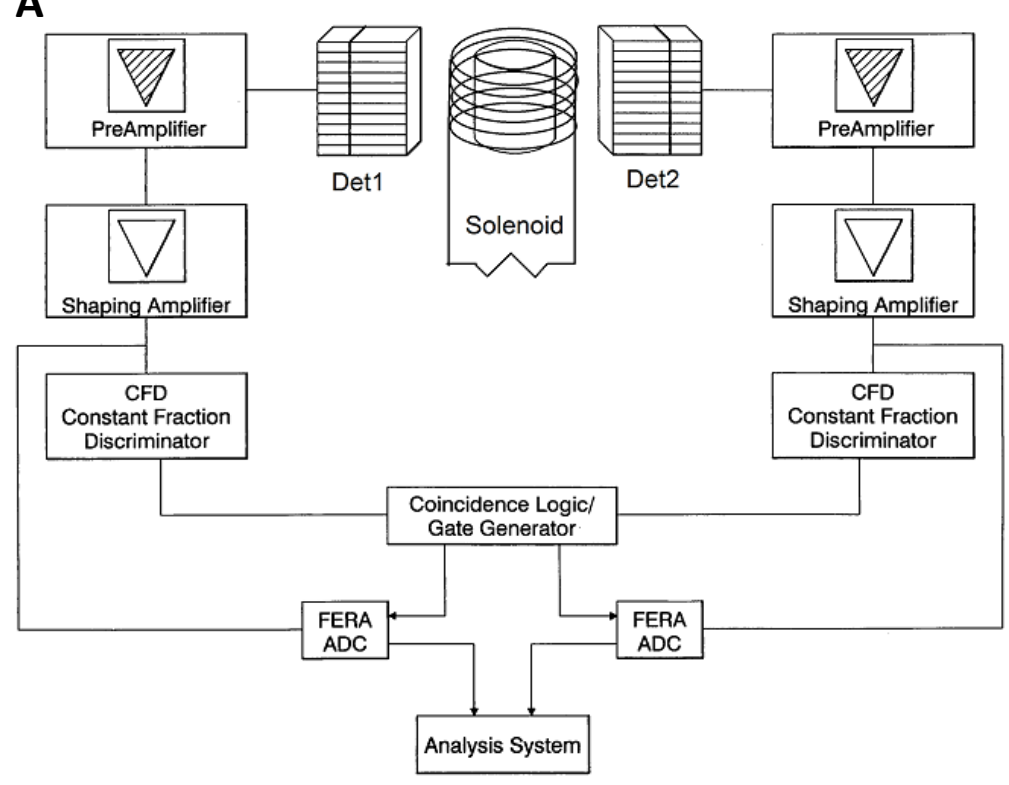

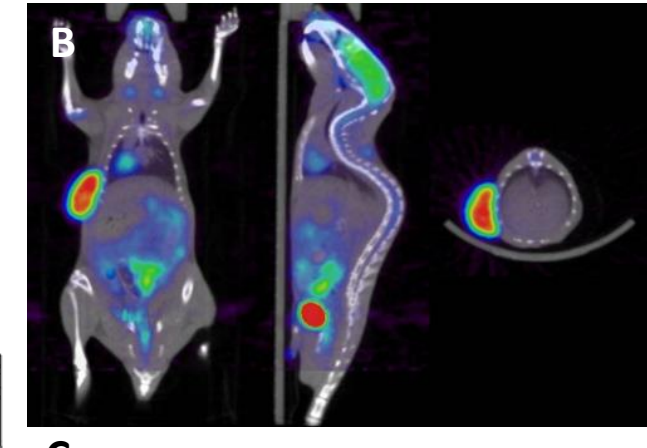

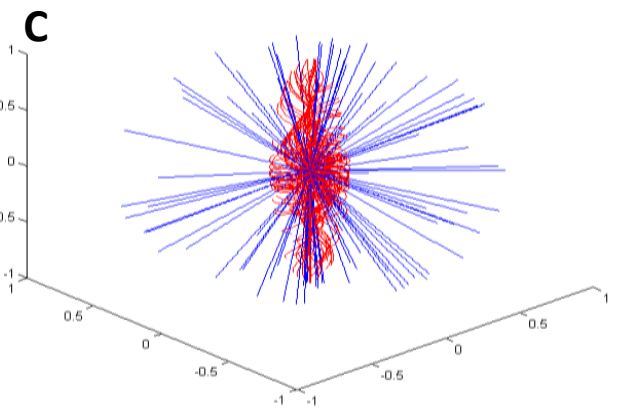

Fig 3. The potential function of a portable simultaneous PET/MR scanner. A) Theoretical design abstraction of a portable simultaneous PER/MR scanner. B) Example output of a small-animal PET/MR scan. ${ }^{142}$ C) Monte Carlo simulation comparing the positron pathlengths in traditional PET (blue) and simultaneous PET/MR (red), illustrating a greatly-increased resolution in PET/MR.

Simultaneous imaging with PET and MRI combined modalities may become a powerful monitoring technique for the functional assessment of engineered muscle tissue - especially in regards to the characterization of engineered muscle glycolosis versus fatty acid metabolism. However, to accurately discern its utility in this regard, further research on the miniaturization of these scanners for use on engineered tissue constructs will be necessary.

to have efficacy in combination with fluorescence imaging techniques to optimize cellular or material visibility within engineered scaffolds, enabling the investigation of how scaffold porosity and structural architecture can play a role in governing cell morphology ${ }^{75,80,87}$ The overall adaptability of OCT to many different types of investigations, in addition to its being noninvasive, non-destructive, and label-free, makes it an encouraging imaging modality for use in future tissue engineering applications.

\section{Positron Emission Tomography}

Position Emission Tomography (PET) is an extremely valuable clinical diagnostic imaging modality that aims to assess physiological function in situ in the human body in a non-invasive manner. PET relies on the emission of a positron from a radioactive pharmaceutical, or radiopharmaceutical, which then decays into two coincident photons that can be collected and traced by imaging equipment. This technique has been especially useful in the diagnosis of many types of cancer, and has likewise shown efficacy in diagnosing hyperthyroidism and detecting localized inflammation through mapping the distributions of leukocyte. ${ }^{88}$ While many radiopharmaceuticals may be used as Fluorine ${ }^{18}$ positron emitters (Table 1), the most common by far is ${ }^{18} \mathrm{~F}$-fluorodeoxyglucose (FDG) which, as a functional glucose analogue, may be used as a direct metric for cellular glycolysis - even from extremely low cell concentrations. ${ }^{89-91}$

PET imaging in accordance with the use of FDG could provide considerably more information when measuring the metabolic capacity of engineered tissue constructs. However, even the smallest commerciallyavailable PET scanners, typically used in nuclear medicine departments in veterinary facilities, are excessively bulky to directly be repurposed for small tissue construct imaging. Additionally, average system resolutions for these scanners are typically on the order of $4.5-5.0 \mathrm{~mm}$ and would thereby be ineffectual for resolving important details in tissue engineered constructs any smaller than this size. ${ }^{5}$ Design proposals therefore must include some method of controlling the resolution loss attributed to positron blur - the governing source blur in PET imaging.

To ameliorate the reduction of resolution from positron blur, simultaneous imaging with PET and magnetic resonance imaging (MRI) have been proposed and have recently been utilized for small animal studies. ${ }^{93-}$ ${ }^{95}$ The presence of a unidirectional magnetic field was 


\section{Imaging of biomaterials and engineered muscle tissue}

Eur J Transl Myol - Basic Appl Myol 2015; 25 (2): 63-76

originally theorized in combination with PET imaging, ${ }^{96,97}$ but its effects on image resolution have only recently been characterized (Fig. 3). ${ }^{13}$ However, recent advances in the electronics involved with such a system have made it possible to fabricate a working device. In order to construct the proposed device, one would have to take into account issues with function due to the interferences between the PET imaging mechanism and the magnetic field. For instance, PET detectors are typically comprised of scintillation crystals coupled with photomultiplier tubes. The sensitivity of these tubes, along with other electrical and radiofrequency components, towards an magnetic field would be a major constraint, but recently, silicon photomultipliers have been considered for use in combination with magnetic fields present from MRI imaging. ${ }^{98-100}$ These photomultipliers have been shown to be able to resolve most of these issues, as silicon based avalanche photodiodes utilize very short optical fiber bundles, which are not affected by the presence of external electromagnetic field fluxes up to 4.0T.

Simultaneous imaging with PET and MRI combined modalities may become a powerful monitoring technique for the functional assessment of engineered muscle tissue - especially in regards to the characterization of engineered muscle glycolosis versus fatty acid metabolism. However, to accurately discern its utility in this regard, further research on the miniaturization of these scanners for use on engineered tissue constructs will be necessary

\section{Bioluminescent Imaging}

Bioluminescent Imaging (BLI) is an imaging technique that relies on emitted light from the enzymatic generation of luminescence in living organisms. BLI typically requires the introduction of the luciferase gene from Photinus pyralis into a receptive cell line or tissue. The luciferase and luciferin reaction results in the emission of photons from 500-620 nm (blue-green to yellow-orange) wavelengths, with peak emission at $612 \mathrm{~nm}$ at $37 \mathrm{C} .{ }^{101,102}$ However, luciferase from the Renilla wildtype emits light from 460-490 nm. ${ }^{103,104}$ Additionally, small genetic changes in these luciferase reporters' encoding DNA can be made to adjust their emission wavelengths without significant changes to the biochemical reaction - thereby allowing for the potential to utilize multiple luciferase reporters in the same engineered tissue to simultaneously investigate multiple biological processes. ${ }^{45}$ Aside from transfection, luciferase may be introduced to tissue via simple diffusion - a technique employed by many investigations to characterize perfusion in vascularized tissue constructs or live animal models. ${ }^{101,105}$

Many studies utilize BLI to track cells following implantation, providing detailed information on cell viability, migration, differentiation, and integration with surrounding scaffolds and/or tissues. ${ }^{88,106,107}$ Additionally, stem cell viability, migration, and proliferation have been monitored for months using BLI on various engineered polymer scaffolds in both bioreactor and non-bioreactor culture conditions. ${ }^{108-110}$ The potential for lengthy investigations has given rise to many current projects aiming to monitor temporal changes in not only cytotoxicity, but also cell gene expression, the progression of infection, and the growth and angiogenesis of tumors. ${ }^{111}$ Investigations on the formation of bone in mice in vivo have likewise relied on luciferase transfection to gauge the degree to which bone formation from extant bone and introduced stem cell sources occurred. ${ }^{88,106,112-114}$ BLI has recently become a modality of great interest from within the tissue engineering community - primarily for its noninvasive, non-destructive, and longitudinal imaging of cells and engineered tissue, both in vivo and in vitro. However, transfection of a luciferase reporter gene is invasive and potentially destructive to target cells and tissues, and spatial information is limited to two dimensions. Current BLI research calls for the development of optimum luciferase transfection or introduction strategies, along with an imaging system that allows for simultaneous 3D spatial acquisition.

\section{Micro X-ray Computed Tomography}

Micro X-ray Computer Tomography $(\mu \mathrm{CT})$ is another promising imaging modality for the functional assessment of engineered tissue, as it allows for the non-destructive quantification of many aspects of engineered scaffolds, such as porosity, pore size, and interconnectivity. ${ }^{115-122}$ Inferring cellular integration and interaction with its engineered scaffold is made possible in $\mu \mathrm{CT}$, as images can be acquired sequentially over time with minimal negative affects to cells from X-ray dose. ${ }^{123,124}$ However, in order to achieve suffiecient X-ray absorption (contrast), soft tissues and biomaterials oftentimes need to be freezedried or kept under dry conditions instead of standard culture conditions - a notion which can significantly affect certain cell or tissue types. Due to this X-ray absorption issue, $\mu \mathrm{CT}$ is most commonly associated with the characterization of engineered bone tissue, as the comparatively high X-ray absorption of calcium eliminates the need for freeze-drying in mineralized tissues and hydrogels (Fig. 4). ${ }^{125,126}$ In these types of studies, $\mu \mathrm{CT}$ can allow the for noninvasive, nondestructive, and label-free assessment of mineralization as a function of time with minimal affect to the tissue or engineered construct being imaged. ${ }^{127,128}$.

In studies involving on-mineralized tissue, many techniques have otherwise been imployed to minimize the aforementioned negative affects of conventional $\mu \mathrm{CT}$ use. For example, contrast agents such as heavy metal, barium sulfate, or Microfil may be used to image anything from 3D scaffold architectures to blood vessel or neural tissue integration and neovascularization within engineered tissues. ${ }^{129-134}$ High resolution $\mu \mathrm{CT}$ has also been utilized in vivo to 

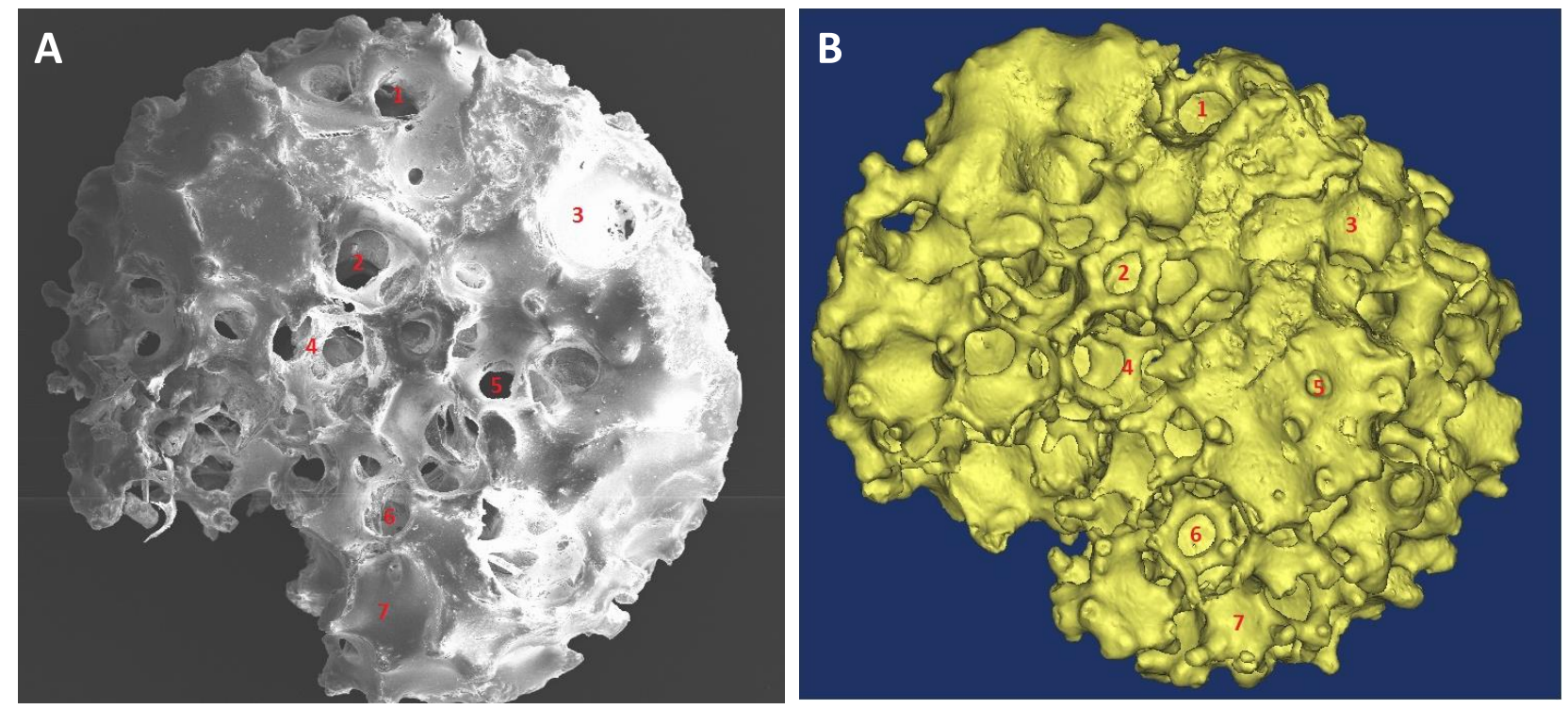

Fig 4. $\mu C T$ image and its corresponding $3 D$ model of an implantable biomaterial scaffold. A) $\mu C T$ image of an engineered bone construct with $\boldsymbol{B})$, its corresponding $3 D$ model.

identify stem cells that were labeled with magnetic nanoparticles following an intra-arterial transplant. ${ }^{135}$ http://www.ncbi.nlm.nih.gov/pmc/article s/PMC3799904/ - R180 However, the use of contrast agents, dyes, or radioactive labels always results in the destruction of engineered tissue, so functional assessment of engineered constructs or post-transplant engineered tissues is limited to longitudinal studies assessing multiple timepoints from individual subjects or constructs.

\section{Conclusions}

The impact that the aforementioned imaging modalities have on muscle tissue engineering is constantly growing. The impressive advances of electron microscopy $3 \mathrm{D}$ reconstruction of molecular and supramolecular fine details of muscle fibers are well exemplified in the first issue of the EJTM Special mini-series "News on Muscle imaging". ${ }^{145-150}$

Further, there are pressing needs for the noninvasive, non-destructive, real-time methods for the functional assessment of cells and tissues. As it currently stands, imaging modalities such as PAM, FLIM, and BLI seem optimally suited for in vitro application due to their depth of resolution limitations, whereas $\mu \mathrm{CT}$, OCT, TPEF, and PET are making great strides towards being relevant in large-muscle construct or in vivo work. However, promising new analysis methods and/or combinations of these modalities offer exciting glimpses at their future applicability to a wide range of myology studies.

In order to translate the basic experimental results of muscle tissue engineering and regenerative myology into the clinical setting, it is critical that researchers identify and exploit the strengths of each of these imaging modalities. Further optimization of these systems will be pivotal in discerning their respective utility in serving the complex and challenging field of tissue engineering. To progress and replace extant methods for functional tissue assessment, the modern imaging systems will need to be highly accurate, reliable, inexpensive, fast and automated. Ideally, these systems must be flexible in applications with traditional in vitro protocols, emerging bioreactor systems and current in vivo studies.

\section{Acknowledgement}

This research has been supported by the University Hospital Landspitali Scientific fund.

\section{Corresponding Author}

Kyle Edmunds

Institute for Biomedical and Neural Engineering, Háskólinn í Reykjavík, Menntavegur 1 - 101 Reykjavík, Iceland Mobile: +001608 7929397

Email: kylejedmunds@gmail.com

Co-Author E-mails: paologar@landspitali.is

\section{References}

1. Bian W, Bursac N. Tissue engineering of functional skeletal muscle: challenges and recent advances. IEEE Eng Med Biol Mag 2008;27:109-13.

2. Alsberg E, Hill EE, Mooney DJ. Craniofacial tissue engineering. Crit Rev Oral Biol Med 2001;12:64-75. 


\section{Imaging of biomaterials and engineered muscle tissue}

Eur J Transl Myol - Basic Appl Myol 2015; 25 (2): 63-76

3. Bach AD, Beier JP, Stern-Staeter J, Horch RE. Skeletal muscle tissue engineering. J Cell Mol Med 2004;8:413-22.

4. Morgan KY, Black LD III. Investigation into the effects of varying frequency of mechanical stimulation in a cycle-by-cycle manner on engineered cardiac construct function. J Tissue Eng Regen Med 2014; 11. doi: 10.1002/term.1915. [Epub ahead of print]

5. Bach AD, Beier JP, Stern-Staeter J, Horch RE. Skeletal muscle tissue engineering. J Cell Mol Med. 2004;8:413-22.

6. DiEdwardo CA, Petrosko P, Acarturk TO, et al. Muscle tissue engineering. Clin Plast Surg. 1999;26:647-56.

7. Vilquin JT. Myoblast transplantation: Clinical trials and perspectives. A mini review. Acta Myol. 2005;24:119-127.

8. Mouly V, Aamiri A, Perie S, et al. Myoblast transfer therapy: Is there any light at the end of the tunnel? Acta Myol 2005;24:128-133.

9. Vandenburgh HH. Functional assessment and tissue design of skeletal muscle. Ann NY Acad Sci 2002;961:201-2.

10. Law PK, Goodwin TG, Fang Q, et al. Cell transplantation as an experimental treatment for Duchenne muscular dystrophy. Cell Transplant 1993;2:485-505.

11. Urish K, Kanda Y, Huard J. Initial failure in myoblast transplantation therapy has led the way toward the isolation of muscle stem cells: Potential for tissue regeneration. Curr Top Dev Biol 2005;68:263-80.

12. $\mathrm{Qu} \mathrm{Z}$, Balkir L, van Deutekom JC, et al. Development of approaches to improve cell survival in myoblast transfer therapy. J Cell Biol 1998;2:1257-67.

13. Pancrazio JJ, Wang F, Kelley CA. Enabling tools for tissue engineering. Biosens Bioelectron 2007;22:2803-11.

14. Assmann A, Akhyari P, Delfs C, et al. Development of a growing rat model for the in vivo assessment of engineered aortic conduits. J Surg Res 2012;176:367-75.

15. Williams C, Quinn KP, Georgakoudi I, Black LD III. Young developmental age cardiac extracellular matrix promotes the expansion of neonatal cardiomyocytes in vitro. Acta Biomater 2014;10:194-204.

16. Van Meerloo J, Kaspers GJ, Cloos J. Cell sensitivity assays: the MTT assay. Methods Mol Biol 2011;731:237-45.

17. Chemaly ER, Yoneyama R, Frangioni JV, Hajjar RJ. Tracking stem cells in the cardiovascular system. Trends Cardiovasc Med 2005;15:297-302.

18. Morawski AM, Lanza GA, Wickline SA. Targeted contrast agents for magnetic resonance imaging and ultrasound. Curr Opin Biotechnol 2005;16:89-92

19. Martin Y, Vermette P. Bioreactors for tissue mass culture: design, characterization, and recent advances. Biomaterials 2005;26:7481503.

20. de Boer J, van Blitterswijk C, Löwik C. Bioluminescent imaging: emerging technology for non-invasive imaging of bone tissue engineering. Biomaterials 2006;27:1851-8. Epub 2005 Oct 20.

21. Stringari C, Cinquin A, Cinquin O, et al. Phasor approach to fluorescence lifetime microscopy distinguishes different metabolic states of germ cells in a live tissue. Proc Natl Acad Sci U S A 2011;108(33):13582-7.

22. Kasischke KA, Vishwasrao HD, Fisher PJ, et al. Neural activity triggers neuronal oxidative metabolism followed by astrocytic glycolysis. Science 2004;305(5680):99-103.

23. Skala MC, Riching KM, Gendron-Fitzpatrick $A$, et al. In vivo multiphoton microscopy of NADH and FAD redox states, fluorescence lifetimes, and cellular morphology in precancerous epithelia. Proc Natl Acad Sci USA 2007;104:19494-9.

24. König K, Uchugonova A, Gorjup E. Multiphoton fluorescence lifetime imaging of 3D-stem cell spheroids during differentiation. Microsc Res Tech 2011;74:9-17.

25. Bird DK, Yan L, Vrotsos KM, et al. Metabolic mapping of MCF10A human breast cells via multiphoton fluorescence lifetime imaging of the coenzyme NADH. Cancer Res 2005;65:8766-73.

26. Uchugonova A, König K. Two-photon autofluorescence and second-harmonic imaging of adult stem cells. J Biomed Opt 2008;13:054068.

27. Guo HW, Chen CT, Wei YH, et al. Reduced nicotinamide adenine dinucleotide fluorescence lifetime separates human mesenchymal stem cells from differentiated progenies. J Biomed Opt 2008;13:050505.

28. Rice WL, Kaplan DL, Georgakoudi I. Twophoton microscopy for non-invasive, quantitative monitoring of stem cell differentiation.PLoS ONE 2010;5:e10075.

29. Kantelhardt SR, Leppert J, Krajewski J, et al. Imaging of brain and brain tumor specimens by time-resolved multiphoton excitation microscopy ex vivo. Neuro-oncol 2007;9:10312.

30. Multi-agency tissue engineering science: a foundation for the future. Advancing tissue science and engineering: a multi-agency strategic plan, published by the National Science and Technology Council, June 8, 2007. 


\section{Imaging of biomaterials and engineered muscle tissue}

Eur J Transl Myol - Basic Appl Myol 2015; 25 (2): 63-76

31. Chance B, Baltscheffsky H. Respiratory enzymes in oxidative phosphorylation. VII. binding of intramitochondrial reduced pyridine nucleotide. J Biol Chem 1958;233:736-9.

32. Chance B, Oshino N, Sugano T, Mayevsky A. Basic principles of tissue oxygen determination from mitochondrial signals. Adv Exp Med Biol 1973;37A:277-92.

33. Chance B, Lieberman M. Intrinsic fluorescence emission from the cornea at low temperatures: Evidence of mitochondrial signals and their differing redox states in epithelial and endothelial sides. Exp Eye Res 1978;26:111117.

34. Mayevsky A, Rogatsky GG. Mitochondrial function in vivo evaluated by NADH fluorescence: From animal models to human studies. Am J Physiol Cell Physiol 2007;292:C615-40.

35. Vergen J, Hecht C, Zholudeva LV. Metabolic imaging using two-photon excited NADH intensity and fluorescence lifetime imaging. Microsc Microanal 2012;18:761-70.

36. Skala M, Ramanujam N. Multiphoton redox ratio imaging for metabolic monitoring in vivo. Methods Mol Biol 2010;594:155-62.

37. Smith J, Ladi E, Mayer-Proschel M, Noble M. Redox state is a central modulator of the balance between self-renewal and differentiation in a dividing glial precursor cell. Proc Natl Acad Sci USA 2000;97:10032-7.

38. Skala MC, et al. In vivo multiphoton microscopy of NADH and FAD redox states, fluorescence lifetimes, and cellular morphology in precancerous epithelia. Proc Natl Acad Sci USA 2007;104:19494-9.

39. Georgakoudi I, Quinn KP. Optical imaging using endogenous contrast to assess metabolic state. Annu Rev Biomed Eng 2012;14:351-67.

40. Quinn KP, Sridharan GV, Hayden RS, et al. Quantitative metabolic imaging using endogenous fluorescence to detect stem cell differentiation. Sci Rep 2013;3:3432.

41. Denk W, Strickler JH, Webb WW. Two-photon laser scanning fluorescence microscopy. Science 1990;248:73-6.

42. Huang S, Heikal AA, Webb WW. Two-photon fluorescence spectroscopy and microscopy of $\mathrm{NAD}(\mathrm{P}) \mathrm{H}$ and flavoprotein. Biophys $\mathbf{J}$ 2002;82:2811-25.

43. Squirrell JM, Wokosin DL, White JG, Bavister BD. Long-term two-photon fluorescence imaging of mammalian embryos without compromising viability. Nat Biotechnol 1999;17:763-7.

44. Zipfel WR, Williams RM, Christie R, et al. Live tissue intrinsic emission microscopy using multiphoton-excited native fluorescence and second harmonic generation. Proc Natl Acad Sci U S A 2003;100:7075-80.

45. Blinova K, Combs C, Kellman P, Balaban RS. Fluctuation analysis of mitochondrial NADH fluorescence signals in confocal and two-photon microscopy images of living cardiac myocytes. J Microsc 2004;213:70-75.

46. An J, Camara AK, Rhodes SS, et al. Warm ischemic preconditioning improves mitochondrial redox balance during and after mild hypothermic ischemia in guinea pig isolated hearts. Am J Physiol Heart Circ Physiol 2005;288:H2620-H2627.

47. Rocheleau JV, Head WS, Piston DW. Quantitative NAD $(\mathrm{P}) \mathrm{H} /$ flavoprotein autofluorescence imaging reveals metabolic mechanisms of pancreatic islet pyruvate response. J Biol Chem 2004;279:31780-31787.

48. Romashko DN, Marban E, O'Rourke B. Subcellular metabolic transients and mitochondrial redox waves in heart cells. Proc Natl Acad Sci U S A 1998;95:1618-23.

49. Kasischke KA, Vishwasrao HD, Fisher PJ, et al. Neural activity triggers neuronal oxidative metabolism followed by astrocytic glycolysis. Science 2004;305:99-103.

50. Vishwasrao HD, Heikal AA, Kasischke KA, Webb WW. Conformational dependence of intracellular NADH on metabolic state revealed by associated fluorescence anisotropy. J Biol Chem 2005;280:25119-26.

51. Piston DW, Masters BR, Webb WW. Threedimensionally resolved $\mathrm{NAD}(\mathrm{P}) \mathrm{H}$ cellular metabolic redox imaging of the in situ cornea with two-photon excitation laser scanning microscopy. J Microsc 1995;178 ( Pt 1):20-27.

52. Levene MJ, Dombeck DA, Kasischke KA, et al. In vivo multiphoton microscopy of deep brain tissue. J Neurophysiol 2004;91:1908-12.

53. Wang LV, Hu S. Photoacoustic tomography: in vivo imaging from organelles to organs. Science 2012;335:1458-62.

54. Su JL, Wang B, Wilson KE, et al. Advances in clinical and biomedical applications of photoacoustic imaging. Expert Opin Med Diagn 2010;4:497-510.

55. Gamelin J, Maurudis A, Aguirre A, et al. A real-time photoacoustic tomography system for small animals. Opt Express 2009;17:10489-98.

56. Cai X, Zhang Y, Li L, Choi SW, et al. Investigation of neovascularization in threedimensional porous scaffolds in vivo by a combination of multiscale photoacoustic microscopy and optical coherence tomography. Tissue Eng Part C Methods 2013;19:196-204.

57. Cai X, Li L, Krumholz A, Guo Z, et al. Multiscale molecular photoacoustic tomography of gene expression. PloS ONE. 2012;7:e43999. 


\section{Imaging of biomaterials and engineered muscle tissue}

Eur J Transl Myol - Basic Appl Myol 2015; 25 (2): 63-76

58. Jose J, Manohar S, Kolkman RG, et al. Imaging of tumor vasculature using Twente photoacoustic systems. J Biophotonics 2009;2:701-17.

59. Siphanto RI, Thumma KK, Kolkman RG, et al. Serial noninvasive photoacoustic imaging of neovascularization in tumor angiogenesis. Opt Express 2005; 13:89-95.

60. Zhang Y, Cai X, Choi SW, et al. Chronic labelfree volu-metric photoacoustic microscopy of melanoma cells in three-dimensional porous scaffolds. Biomaterials 2010;31:8651-8.

61. Nam SY, Mallidi S, Zhang G, et al. Ultrasound and photoacoustic imaging to monitor vascular growth in tissue engineered constructs. Proc SPIE 2009;7179.

62. Pan D, Pramanik M, Senpan A, et al. Molecular photoacoustic imaging of angiogenesis with integrin-targeted gold nano-beacons. FASEB J 2011;25:875-82.

63. Kim S, Chen YS, Luke GP, Emelianov SY. In vivo three-dimensional spectroscopic photoacoustic imaging for monitoring nanoparticle delivery. Biomed Opt Express 2011;2:2540-50.

64. Chung E, Nam SY, Ricles LM, et al. Evaluation of gold nanotracers to track adipose-derived stem cells in a pegylated fibrin gel for dermal tissue engineering applications. Int $\mathbf{J}$ Nanomed 2013;8:325-36.

65. Nam SY, Ricles LM, Suggs L, Emelianov SY. In vivo ultrasound and photo-acoustic monitoring of mesenchymal stem cells labeled with gold nanotracers. PloS ONE. 2012;7:e37267.

66. Helmchen F, Denk W. Deep tissue two-photon microscopy. Nat Methods 2005;2:932-40.

67. Stringari C, Sierra R, Donovan PJ, Gratton E. Label-free separation of human embryonic stem cells and their differentiating progenies by phasor fluorescence lifetime microscopy. J Biomed Opt 2012;17:046012 doi: 10.1117/1.JBO.17.4.046012.

68. Konig K., Uchugonova A, Gorjup E. Multiphoton fluorescence lifetime imaging of 3D-stem cell spheroids during differentiation. Microsc Res Tech 2011;74:9.

69. Yu Q, Heikal A. Two-photon autofluorescence dynamics imaging reveals sensitivity of intracellular NADH concentration and conformation to cell physiology at the singlecell level. J Photochem Photobiol B 2009;95:46-7.

70. Blacker TS, Mann ZF, Gale JE, et al. Separating $\mathrm{NADH}$ and NADPH fluorescence in live cells and tissues using FLIM. Nat Commun $2014 ; 5: 3936$
71. Zheng K, Rupnick MA, Liu B, Brezinski ME. Three dimensional OCT in the engineering of tissue constructs: a potentially powerful tool for assessing optimal scaffold structure. Open Tissue Eng Regen 2009;2: 8-13.

72. Brezinski ME. Optical coherence tomography for identifying unstable coronary plaque. Int $\mathbf{J}$. Cardiol 2006;107:154-65.

73. Huang D, Swanson EA, Lin CP, et al. Optical coherence tomography. Science 1991;254,117880.

74. Boppart S, Oldenburg A, Xu C, Marks D. Optical probes and techniques for molecular contrast enhancement in coherence imaging. J Biomed. Opt 2005; 10, 41208.

75. Liang $\mathrm{X}$, Graf BW, Boppart SA. Imaging engineered tissues using structural and functional optical coherence tomography.J Biophotonics 2009;2:643-55.

76. Zheng K, Rupnick MA, Liu B, Brezinski ME. Three dimensional OCT in the engineering of tissue constructs: a potentially powerful tool for assessing optimal scaffold structure.Open Tissue Eng Regen Med J 2009;2:8-13.

77. Saidha S, Eckstein C, Ratchford J. Optical coherence tomography for the detection of axonal damage in multiple sclerosis. Ophthalmology 2010;20:77-88

78. Chen W-L, Huang C-H, Chiou L-L, et al. Multiphoton imaging and quantitative analysis of collagen production by chondrogenic human mesenchymal stem cells cultured in chitosan scaffold. Tissue Eng C, Methods 2010;16, 91320.

79. Smith LE, Smallwood R, Macneil S. A comparison of imaging methodologies for 3D tissue engineering. Microsc Res Tech 2010;73,1123-33

80. Tan W, Oldenburg AL, Norman JJ, et al. Optical coherence tomography of cell dynamics in three-dimensional tissue models. Opt Express 2006;14:7159-71.

81. Xu X, Wang RK, El Haj A. Investigation of changes in optical attenuation of bone and neuronal cells in organ culture or threedimensional constructs in vitro with optical coherence tomography: relevance to cytochrome oxidase monitoring.Eur Biophys J 2003;32:355-62.

82. Woiciechowsky C, Abbushi A, Zenclussen ML, et al. Regeneration of nucleus pulposus tissue in an ovine intervertebral disc degeneration model by cell-free resorbable polymer scaffolds. J. Tissue Eng. Regen. Med 2012;10.1002.

83. Yang Y, Bagnaninchi PO, Ahearne M, et al. A novel optical coherence tomography based micro-indentation technique for mechanical 


\section{Imaging of biomaterials and engineered muscle tissue}

Eur J Transl Myol - Basic Appl Myol 2015; 25 (2): 63-76

characterization of hydrogels. J R Soc Interface 4 2007;1169-73.

84. Ishii $\mathrm{K}, \mathrm{Ma} \mathrm{Z}$, Ninomiya $\mathrm{T}$, et al. Control of guided hard tissue regeneration using phosphorylated gelatin and OCT imaging of calcification. Prog Biomed Opt Imaging Proc 2007;SPIE 6439: 64390D.

85. Smith LE, Bonesi M, Smallwood R, et al. Using swept-source optical coherence tomography to monitor the formation of neo-epidermis in tissue-engineered skin. J. Tissue Eng. Regen. Med 2010;4, 652-8.

86. Yang Y, Dubois A, Qin XP, et al. Investigation of optical coherence tomography as an imaging modality in tissue engineering. Phys Med Biol 2006;51:1649-59.

87. Chen C-W, Betz MW, Fisher JP, et al. Macroporous hydrogel scaffolds and their characterization by optical coherence tomography. Tissue Eng Part C Methods 2011;17:101-12.

88. Villa C, Erratico S, Razini $\mathrm{P}$, et al. In vivo tracking of stem cell by nanotechnologies: future prospects for mouse to human translation. Tissue Eng Part B Rev 2011;17:1-11.

89. Hendee WR, Cleary K, Ehman RL, et al. Bioengineering and imaging research opportunities workshop V: a summary on imaging and characterizing structure and function in native and engineered tissues. Cytometry A 2008;73:779-84.

90. Nieuwoudt M, Wiggett S, Malfeld S, van der Merwe SW. Imaging glucose metabolism in perfluorocarbon-perfused hepatocyte bioreactors using positron emission tomography. J Artif Organs 2009;12:247.

91. Chouinard JA, Rousseau JA, Beaudoin JF, et al. Positron emission tomography detection of human endothelial cell and fibroblast monolayers: effect of pretreatment and cell density on 18FDG uptake.Vasc Cell. 2012;4:5.

92. Radiological Society of North America. Target Pathophysiologies of Radiopharmaceuticals. 2012. Issue 5.

93. Mackewn JE, Strul D; Hallett WA, et al. Design and development of an MR-compatible PET scanner for imaging small animals. Nuclear Science, IEEE Transactions on 2005;52:376-80.

94. Zaidi H, Montandon ML. The new challenges of brain PET imaging technology. Current Medical Imaging Reviews 2006;2: 3-13.

95. Schulz D, Southekal S, Junnarkar SS, et al. Simultaneous assessment of rodent behavior and neurochemistry using a miniature positron emission tomograph. Nature Meth 2011; 8:347352 doi:10.1038/nmeth. 1582

96. Zaidi H, Mawlawi O, Orton CG. Simultaneous $\mathrm{PET} / \mathrm{MR}$ will replace PET/CT as the molecular multimodality imaging platform of choice. Medical Physics-New York-Institute of Physics 2007;34:1525-8.

97. Iida $\mathrm{H}$, Kanno $\mathrm{S}$, Miuri $\mathrm{S}$, et al. A simulation study of a method to reduce positron annihilation spread distributions using a strong magnetic field in positron emission tomography. IEEE Trans. Nucl. Sci 1986;33:597-600.

98. McElroy D, Saveliev V, Reznika A, Rowlands J. Evaluation of silicon photomultipliers: a promising new detector for MR compatible PET. Nucl.Instrum. Meth. A, 2007;571:106-9.

99. Roncali E, Cherry SR. Application of silicon photomultipliers to positron emission tomography. Ann Biomed Eng 2011;39:135877.

100. Yoon HS, Ko GB; Kwon SI, et al. Initial results of simultaneous PET/MRI experiments with an MRI-compatible silicon photomultiplier PET scanner. Journal of Nuclear Medicine 2012;53:608-14.

101. Honigman A, Zeira E, Ohana P, et al. Imaging transgene expression in live animals. Mol Ther 2001;4: 239-249.

102. Zhao H, Doyle TC, Coquoz O, et al. Emission spectra of bioluminescent reporters and interaction with mammalian tissue determin the sensitivity of detection in vivo. J Biomed Opt 2005; 10: $041210 \quad$ (August 24, 2005). doi:10.1117/1.2032388.

103. Hastings JW. Chemistries and colors of bioluminescent reactions: a review. Gene 1996;173:5-11.

104. Roda M Guardigli, E Michelini, M Mirasoli A. Bioluminescence in analytical chemistry and in vivo imaging. Trends Anal. Chem., 2009. 28(3): p. 307-322.

105. Levenberg S, Rouwkema J, Macdonald M, et al. Engineering vascularized skeletal muscle tissue. Nat Biotechnol 2005;23:879-884.

106. De Boer J, van Blitterswijk C, Lowik C. Bioluminescent imaging: emerging technology for non-invasive imaging of bone tissue engineering. Biomaterials 2006;27:1851-8.

107. Bago JR, Aguilar E, Alieva M, et al. In vivo bioluminescence imaging of cell differentiation in biomaterials: a platform for scaffold development. Tissue Eng Part A 2013;19:593603.

108. Hwang do W, Jang SJ, Kim YH, et al. Realtime in vivo monitoring of viable stem cells implanted on biocompatible scaffolds. Eur J Nucl Med Mol Imaging 2008;35:1887-98.

109. Logeart-Avramoglou D, Oudina K, Bourguignon $\mathrm{M}$, et al. In vitro and in vivo bioluminescent quantification of viable stem 


\section{Imaging of biomaterials and engineered muscle tissue}

Eur J Transl Myol - Basic Appl Myol 2015; 25 (2): 63-76

cells in engineered constructs. Tissue Eng Part C Methods 2010;16:447-58.

110. Roman I, Vilalta M, Rodriguez J, et al. Analysis of progenitor cell-scaffold combinations by in vivo non-invasive photonic imaging. Biomaterials 2007;28:2718-28.

111. Rice BW, Cable MD, Nelson MB. In vivo imaging of light-emitting probes. J. Biomed Opt 2001:432-440.

112. Geuze RE, Prins H-J, Oner FC, et al. Luciferase labeling for multipotent stromal cell tracking in spinal fusion versus ectopic bone tissue engineering in mice and rats. Tissue Eng Part A 2010;16:3343-51.

113. Prins H-J, Fernandes H, Rozemuller H, et al. Spatial distribution and survival of human and goat mesenchymal stromal cells on hydroxyapatite and b-tricalcium phosphate. J Tissue Eng Regen Med. 2012. Dec 18. doi: 10.1002/term.1681.

114. Geuze RE, Prins H-J, Oner FC, et al. Luciferase labeling for multipotent stromal cell tracking in spinal fusion versus ectopic bone tissue engineering in mice and rats. Tissue Eng Part A 2010;16:3343-51.

115. Alberich-Bayarri A, Moratal D, Escobar Ivirico $\mathrm{JL}$, et al. Microcomputed tomography and microfinite element modeling for evaluating polymer scaffolds architecture and their mechanical properties. J Biomed Mater Res B Appl Biomater 2009;91:191-202.

116. Chimenti I, Rizzitelli G, Gaetani R, et al. Human cardiosphere-seeded gelatin and collagen scaffolds as cardiogenic engineered bioconstructs. Biomaterials 2011;32:9271-81.

117. Ho ST, Hutmacher DW. A comparison of micro CT with other techniques used in the characterization of scaffolds. Biomaterials 2006;27:1362-76.

118. Landis FA, Stephens JS, Cooper JA, et al. Tissue engineering scaffolds based on photocured dimethacrylate polymers for in vitro optical imaging. Biomacromolecules 2006;7:1751-7.

119. Muller B, Beckmann F, Huser M, et al. Nondestructive three-dimensional evaluation of a polymer sponge by micro-tomography using synchrotron radiation. Biomol Eng 2002;19:738.

120. Yang Y, Dorsey SM, Becker ML, et al. X-ray imaging optimization of 3D tissue engineering scaffolds via combinatorial fabrication methods. Biomaterials 2008;29:1901-11.

121. Patel ZS, Ueda H, Yamamoto $\mathrm{M}$, et al. In vitro and in vivo release of vascular endothelial growth factor from gelatin microparticles and biodegradable composite scaffolds. Pharm Res 2008;25:2370-8
122. Gargiulo P, Helgason T, Ramon C, et al. CT and MRI assessment and characterization using segmentation and 3D modeling techniques: applications to muscle, bone and brain. Eur $\mathrm{J}$ Transl Myol - Basic Appl Myol 2014;24:55-62.

123. Behravesh E, Timmer MD, Lemoine JJ, et al. Evaluation of the in vitro degradation of macroporous hydrogels using gravimetry, confined compression testing, and microcomputed tomography. Biomacromolecules 2002;3:1263-70

124. Hedberg EL, Shih CK, Lemoine JJ, et al. In vitro degradation of porous poly(propylene fumarate)/poly(dl-lactic-co-glycolic acid) composite scaffolds. Biomaterials 2005;26:3215-25.

125. Cartmell S, Huynh K, Lin A, et al. Quantitative micro-computed tomography analysis of mineralization within three-dimensional scaffolds in vitro. J Biomed Mater Res A 2004;69:97-104.

126. Chatterjee K, Lin-Gibson S, Wallace WE, et al. The effect of 3D hydrogel scaffold modulus on osteoblast differentiation and mineralization revealed by combinatorial screening. Biomaterials 2010;31:5051-62.

127. van Lenthe $\mathrm{GH}$, Hagenmüller $\mathrm{H}$, Bohner $\mathrm{M}$, et al. Nondestructive micro-computed tomography for biological imaging and quantification of scaffold-bone interactions in vivo. Biomaterials 2007;28:2479-90

128. Porter BD, Lin AS, Peister A, et al. Noninvasive image analysis of 3D construct mineralization in a perfusion bioreactor. Biomaterials 2007; 28:2525-33.

129. Faraj KA, Cuijpers V, Wismans RG, et al. Micro-computed tomographical imaging of soft biological materials using contrast techniques. Tissue Eng Part C Methods 2009;15:493-9.

130. Arkudas A, Beier J, Pryymachuk G, et al. Automatic quantitative micro-computed tomography evaluation of angiogenesis in an axially vascularized tissue-engineered bone construct. Tissue Eng Part C Methods 2010;16:1503-14.

131. Ji C, Khademhosseini A, Dehghani F. Enhancing cell penetration and proliferation in chitosan hydrogels for tissue engineering applications. Biomaterials 2011;32:9719-29.

132. Zou D, Zhang Z, He J, et al. Blood vessel formation in the tissue-engineered bone with the constitutively active form of HIF-1a mediated BMSCs. Biomaterials 2012;33:2097-108.

133. Young S, Kretlow JD, Nguyen C, et al. Microcomputed tomography characterization of neovascularization in bone tissue engineering applications. Tissue Eng Part B Rev 2008;14:295-306. 


\section{Imaging of biomaterials and engineered muscle tissue}

Eur J Transl Myol - Basic Appl Myol 2015; 25 (2): 63-76

134. Watling CP, Lago N, Benmerah S, et al. Novel use of X-ray micro computed tomography to image rat sciatic nerve and integration into scaffold. J Neurosci Methods 2010;188:39-44.

135. Belicchi M, Cancedda R, Cedola A, et al. Some applications of nanotechnologies in stem cells research. Mater Sci Eng B 2009;165:139-47.

136. Mol A, Breuls RGM, Petterson R, Bouten CVC. Quantification of cell viability in engineered tissues. Eindhoven University of Technology, Department of Biomedical Engineering. Accessed from: http://repository.tue.nl/posters/738771.pdf

137. Juhas M, Engelmayr GC Jr, Fontanella AN, et al. Biomimetic engineered muscle with capacity for vascular integration and functional maturation in vivo. Proc Natl Acad Sci U S A 2014;111:5508-13.

138. Salem AA. Protocol of Rapid Immunostaining of Lymph Node Touch Imprints. The Royal College of Surgeons in Edinburgh. Accessed from:

http://www.rcsed.ac.uk/fellows/aaasalem/Rapid _imprint_immunostaining.htm

139. Brescia P, Banks P. Quantifying Cytotoxicity of Thiostrepton on Mesothelioma Cells using MTT Assay and the Epoch ${ }^{\mathrm{TM}}$ Microplate Spectrophotometer. BioTek Instruments, Inc., Winooski, VT. Accessed from: http://www.biotek.com/resources/articles/quonti fication-cell-viability-epoch.html

140. Jennette JC. Renal Pathology Tutorial. UNC Nephopathology. Accessed from: http://www.uncnephropathology.org/jennette/ch 1.htm

141. Li X, Gianoulis TA, Yip KY, Gerstein M, Snyder M. Extensive in vivo metabolite-protein interactions revealed by large-scale systematic analyses. Cell 2010;143:639-50.

142. Zaidi H. SPECT Quantification. PIN lab: Geneva University Hospital, Division of
Nuclear Medicine. Accessed from: http://pinlab.hcuge.ch/research.html

143. Gargiulo P, Vatnsdal B, Ingvarsson P, et al. Restoration of muscle volume and shape induced by electrical stimulation of denervated degenerated muscles: qualitative and quantitative measurement of changes in rectus femoris using computer tomography and image segmentation. Artif Organs 2008;32:609-13.

144. Gargiulo P, Carraro U, Mandl T, et al. Anthropometry of human muscle using segmentation techniques and 3D modelling: applications to lower motor neuron denervated muscle in Spinal Cord Injury. In Handbook of Anthropometry, Springer, New York, 2012 pp. 323-54.

145. Franzini-Armstrong C, Gargiulo P, Stramare R, Eds. News on Muscle Imaging. Eur J Transl Myol - Basic Appl Myol 2015; 25 (1):5-56.

146. Franzini-Armstrong C Electron microscopy: from 2D to 3D images with special reference to muscle. Eur J Transl Myol - Basic Appl Myol 2015; 25 (2):5-13.

147. Jayasinghe ID, Clowsley AH, Munro M, et al. Revealing t-tubules in striated muscle with new optical super-resolution microscopy techniques. Eur J Transl Myol - Basic Appl Myol 2015;25:15-26.

148. Samsó M. 3D structure of the dihydropyridine receptor of skeletal muscle. Eur J Transl Myol Basic Appl Myol 2015;25:27-33.

149. Baker MR, Fan G, Serysheva II. Single-particle cryo-EM of the ryanodine receptor channel in an aqueous environment. Eur J Transl Myol Basic Appl Myol 2015;25:35-48.

150. Wagenknecht T, Hsieh C, Marko M. Skeletal Muscle triad junction ultrastructure by FocusedIon-Beam milling of muscle and Cryo-Electron Tomography. Eur J Transl Myol - Basic Appl Myol 2015;25:49-56. 